\title{
ICAM-1 expression by lung cancer cell lines: effects of upregula- tion by cytokines on the interaction with LAK cells
}

\author{
M. Melis*, M. Spatafora**, A. Melodia**, E. Pace*, M. Gjomarkaj*, \\ A.M. Merendino**, G. Bonsignore**
}

ICAM-1 expression by lung cancer cell lines: effects of upregulation by cytokines on the interaction with LAK cells. M. Melis, M. Spatafora, A. Melodia, E. Pace, M. Gjomarkaj, A.M. Merendino, G. Bonsignore. (C) ERS Journals Ltd 1996.

ABSTRACT: Intercellular adhesion molecule-1 (ICAM-1) expression by tumour cells may be involved in their interaction with defensive cells.

In this study the surface ICAM-1 expression and soluble ICAM-1 (sICAM-1) production by five small cell lung cancer (SCLC) and five non-SCLC (NSCLC) cell lines was investigated. In addition, the effects of ICAM-1 upregulation by cytokines on the adhesion of lung cancer cells to allogeneic lymphokine-activated killer (LAK) cells and susceptibility to LAK cytotoxicity was also evaluated.

ICAM-1 expression was assessed by flow cytometry. Soluble ICAM-1 release was measured by enzyme-linked immunosorbent assay (ELISA). Interaction with LAK cells was tested by adhesion and cytotoxicity assays.

At baseline, SCLC lines did not express ICAM-1, while 4 of the 5 NSCLC lines expressed ICAM-1. ICAM-1 expression was induced by interferon- $\gamma(\mathrm{IFN}-\gamma)$ in 4 of the 5 SCLC lines and upregulated in 1 of the 5 NSCLC lines. ICAM-1 expression was induced by tumour necrosis factor- $\alpha(\mathrm{TNF}-\alpha)$ in 1 of the 5 SCLC lines (National Cancer Institute (NCI) H211), and upregulated in 2 of the 5 NSCLC lines (NCI H460 and NCI H838). Among the latter lines, one (NCI H838) released significant amounts of sICAM-1. Adhesion to LAK cells and susceptibility to LAK cytotoxicity were significantly higher in TNF- $\alpha$-treated NCI H460 and NCI H211 cells, compared to untreated NCI H460 and NCI H211 cells. In contrast, no difference in adhesion to LAK cells and susceptibility to LAK cytotoxicity was detected between baseline and TNF- $\alpha$-treated NCI H838 cells.

Intercellular adhesion molecule-1 surface expression and soluble intercellular adhesion molecule-1 release may play an important role in interactions between lymphokine-activated killer cells and lung cancer cells.

Eur Respir J., 1996, 9, 1831-1838.

Cell adhesion molecules which mediate cell-cell and cell-matrix interactions play an important role in tumour progression by virtue of their involvement in metastatic processes and in host-tumour interactions [1]. One of these adhesion pathways involves a member of the $\beta_{2}$ integrin subfamily, leucocyte-function associated antigen-1 (LFA-1) or CD11a/CD18 and its principal ligand, intercellular adhesion molecule-1 (ICAM-1) or CD54 [2]. ICAM-1 is constitutively expressed on a variety of inflammatory and immune effector cells and in structural cells, such as: endothelial cells, fibroblasts, and epithelial cells [3]. In addition, ICAM-1 has been detected on the surface of a variety of primary tumours and tumour cell lines, including lymphomas [4], melanomas [5], renal [6], pancreatic [7], bladder [8] and lung carcinomas [9]. Because LFA-1 is expressed on mononuclear phagocytes, cytotoxic T-cells, natural-killer (NK), and lymphokine-activated killer (LAK) cells [1], the expression of ICAM-1 by tumour cells may be involved in the regulation of their susceptibility to cytotoxic activity of autologous and allogeneic defensive cells.

The expression of ICAM-1 is upregulated by a variety of stimuli, including phorbol esters, bacterial lipopolysac-
*Istituto di Fisiopatologia Respiratoria CNR, and **Istituto di Pneumologia dell'Università, Palermo, Italy.

Correspondence: M. Spatafora Istituto di Pneumologia dell'Università Via Trabucco, 180 I-90146 Palermo Italy

Keywords: Cell adhesion molecules lung neoplasm immunology lymphocyte-activated killer cells non-small cell lung cancer small cell lung cancer

Received: June 141995

Accepted after revision June 151996 charide, and inflammatory cytokines, such as tumour necrosis factor- $\alpha$ (TNF- $\alpha$ ) and interferon- $\gamma$ (IFN- $\gamma$ ) [10]. The functional consequences of the regulation of ICAM1 expression on susceptibility of tumour cells to cellmediated cytotoxicity has been investigated in human melanomas. Firstly, the induction of ICAM-1 expression by incubation of melanoma cells with inflammatory cytokines [11], or by transfection of the ICAM-1 gene in ICAM-1-negative melanoma cell lines [12], is followed by increased susceptibility to monocyte cytotoxicity. In addition, anti-CD54 monoclonal antibodies (MoAbs) are able to inhibit the lysis of melanoma cells by autologous tumour-infiltrating lymphocytes, and to a lesser extent, by allogeneic NK and LAK cells [13]. However, the upregulation of ICAM-1 expression on melanoma cells may also be followed by the extracellular release of soluble ICAM-1 (sICAM-1) which, by competition with the membrane-bound ICAM-1, interferes with the physical interaction of $\mathrm{NK}$ and LAK cells with melanoma cells, thus reducing their susceptibility to cytotoxicity [14]. Therefore, shedding of sICAM-1 in the extracellular space may be one of the mechanisms by which tumour cells escape cell-mediated cytotoxicity. Consistent with this 
concept, the release of sICAM-1 by human melanoma cell lines is related to tumour growth in nude mice [15]. Furthermore, patients with advanced malignant melanoma and elevated serum levels of sICAM-1 have a shorter survival than similar patients with normal serum levels of sICAM-1 [16].

The functional consequences of cytokine-induced upregulation of ICAM-1 expression and SICAM-1 release by lung cancer cells are unknown. To address this question, we investigated the surface expression of ICAM-1 and the production of sICAM-1 by five small cell lung cancer (SCLC) and five non-SCLC (NSCLC) cell lines and their modulation by cytokines. A "variant" SCLC cell line (National Cancer Institute (NCI) H211) and two NSCLC cell lines (NCI H460, and NCI H838) with differential patterns of upregulation of ICAM-1 expression were identified. Whilst in all these cell lines inflammatory cytokines upregulated the cell surface expression of ICAM-1, only in NCI H838 was this effect paralleled by the release of SICAM- 1 in culture media. These characteristics of NCI H211, NCI H460 and NCI H838 cells made it possible to investigate the effects of upregulation of ICAM-1 on the adhesion of lung cancer cells to allogeneic LAK cells and their susceptibility to LAK cell-mediated lysis.

\section{Materials and methods}

\section{Cell lines}

Five SCLC cell lines, NCI H69, NCI H526, NCI H187, NCI H146, NCI H211 ("variant" cell line) and four NSCLC cell lines NCI H358, NCI H157, NCI H838, NCI H460 (NSCLC with neuroendocrine features) were kindly provided by D.P. Carbone (National Cancer Institute, Navy Medical Oncology Branch, Bethesda, MD, USA). An additional NSCLC cell line (Sk-Mes-1), the erythroleukaemia cell line K562 (positive control for spontaneous ICAM-1 expression), and the NK-resistant A-549 type-II pneumocyte cell line (positive control for LAK activity) were purchased from American Type Culture Collection (Rockville, MD, USA). While NSCLC grew as adherent monolayers, SCLC cell lines grew in suspension as floating aggregates, with the exception of the "variant" line NCI H211 [17]. "Variant" cell lines, which represent approximately $30 \%$ of SCLC, grow as adherent monolayers, do not express markers of neuroendocrine differentiation, are relatively radio-resistant and have a more rapid growth than "classic" SCLC lines [18]. All cell lines were maintained in RPMI 1640 medium supplemented with $10 \%$ heat-inactivated $\left(56^{\circ} \mathrm{C}\right.$ for $30 \mathrm{~min}$ ) foetal bovine serum (FBS), $1 \%$ penicillin-streptomycin solution and $1 \mathrm{mM} \mathrm{L}$-glutamine (complete medium (CM)) (all from Gibco, Grand Island, NY, USA).

\section{Reagents}

Recombinant human TNF- $\alpha$ (specific activity $8.1 \times 10^{6}$ $\mathrm{U} \cdot \mathrm{mL}^{-1}$ ) was the kind gift of BASF/Knoll (Ludwigshafen, FRG). Recombinant human IFN- $\gamma$ (specific activity $3 \times 10^{7}$ $\mathrm{U} \cdot \mathrm{mg}^{-1}$ ) and recombinant human GM-CSF (specific activity $2.5 \times 10^{7} \mathrm{U} \cdot \mathrm{mg}^{-1}$ ) were supplied by Genzyme (Cambridge, MA, USA). Recombinant human interleukin-2 (IL-2) (specific activity $1.8 \times 10^{7} \mathrm{U} \cdot \mathrm{mg}^{-1}$ ) was obtained from Euro Cetus, Amsterdam, The Netherlands). Phycoerythrin (PE)-conjugated mouse anti-human ICAM-1 MoAb (anti-CD54 - LB2-PE) was purchased from Becton Dickinson, Mountain View, CA, USA. For adhesion and LAK-cytotoxicity assays, the following MoAbs were used: anti-CD54 clone 84H10 (Immunotech, Luminy, Marseille, France); anti-CD11a clone MHM24 and antiCD18 clone MHM23 (both from Dakopatts, Glostrup, Denmark).

\section{Cytofluorimetric analysis}

The expression of ICAM-1 on the surface of SCLC and NSCLC lines was determined by direct immunofluorescence using a FACStar Plus (Becton Dickinson) analyser equipped with an argon ion laser (Innova 70 Coherent) and Consort 32 computer support. Briefly, tumour cells were harvested from culture flasks, washed with phosphate buffered saline (PBS) (Gibco) and vital counts were made by the trypan blue dye-exclusion assay with a haemocytometer. The viability of tumour cells was $>90 \%$. Cells $\left(10^{6} \cdot \mathrm{mL}^{-1}\right)$ were incubated in CM in the absence or presence of TNF- $\alpha\left(250 \mathrm{U} \cdot \mathrm{mL}^{-1}\right)$, IFN$\gamma\left(250 \mathrm{U} \cdot \mathrm{mL}^{-1}\right)$, or GM-CSF $\left(500 \mathrm{U} \cdot \mathrm{mL}^{-1}\right)$ for $16 \mathrm{~h} \mathrm{[10].}$ In preliminary time-response experiments, this incubation time was associated with maximal induction of ICAM-1 membrane expression in the absence of significant cell toxicity. After incubation, tumour cells were harvested with a rubber policeman, washed, resuspended in PBS at the concentration of $10 \times 10^{6} \cdot \mathrm{mL}^{-1}$ and 0.1 $\mathrm{mL}$ aliquots were incubated in the dark $\left(30 \mathrm{~min}\right.$ at $\left.4^{\circ} \mathrm{C}\right)$ with PE- conjugated mouse anti-human ICAM-1 MoAb. PE-conjugated mouse anti-human immunoglobulin G1 (IgG1) (X-928, Dakopatts, Glostrup, Denmark) served as negative control. Results were expressed as mean log fluorescence intensity. Each line was analysed at least twice.

\section{Detection of SICAM-1 by ELISA}

Tumour cells were resuspended in CM $\left(2 \times 10^{5} \cdot \mathrm{mL}^{-1}\right)$ and seeded, in $2 \mathrm{~mL}$ aliquots, in 6 -well culture plates. After $24 \mathrm{~h}$, cells were washed and $2 \mathrm{~mL}$ aliquots of control CM or CM containing TNF- $\alpha\left(250 \mathrm{U} \cdot \mathrm{mL}^{-1}\right)$, or IFN$\gamma\left(250 \mathrm{U} \cdot \mathrm{mL}^{-1}\right)$, or GM-CSF $\left(500 \mathrm{U} \cdot \mathrm{mL}^{-1}\right)$ were added. After an additional $16 \mathrm{~h}$, supernatants were removed, centrifuged and stored at $-80^{\circ} \mathrm{C}$ until assayed. Soluble ICAM1 was measured by a commercially available ELISA Kit (British Bio-technology, Abingdon, UK) [16], following instructions of the manufacturer. The sensitivity of the assay was $<2.5 \mathrm{ng} \cdot \mathrm{mL}^{-1}$. Experiments were performed in duplicate.

\section{Generation of LAK cells}

Heparinized venous blood samples were drawn from normal donors by venipuncture. Human peripheral blood mononuclear (PBM) cells were isolated by centrifugation $(400 \times \mathrm{g}$ for $25 \mathrm{~min})$ on a Ficoll-Hypaque (Pharmacia, Uppsala, Sweden) density gradient, as described previously [19]. After centrifugation, the PBM cells were recovered at the interface of the gradient, 
washed twice with Hanks' balanced salt solution (HBSS) (Gibco) and resuspended in CM at the concentration of $10 \times 10^{6}$ cells $\cdot \mathrm{mL}^{-1}$. LAK cells were generated by incubation $\left(5\right.$ days, $\left.37^{\circ} \mathrm{C}, 5 \% \mathrm{CO}_{2}\right)$ of PBM with recombinant human interleukin-2 (IL-2) $\left(1,000 \mathrm{U} \cdot \mathrm{mL}^{-1}\right)$ [20]. The effectiveness of this procedure was repeatedly checked by testing the ability of the generated LAK cells to exert cytotoxic activity on the NK-resistant A-549 typeII pneumocyte cell line (ATCC) [21].

\section{Adhesion assay}

Adhesion of LAK cells to NCI H460, NCI H211 and NCI H838 cells was studied as described previously [12], with minor modifications. Tumour cells were detached from culture flasks with ethylenediamine tetraacetic acid (EDTA)-trypsin (Gibco) solution, washed, counted, resuspended in $\mathrm{CM}$ at the concentration of $5 \times$ $10^{4}$ cells $\cdot \mathrm{mL}^{-1}$ and $1 \mathrm{~mL}$ aliquots were dispensed in 24well flat-bottomed plates (Linbro). Cells were allowed to adhere to plastic and, after $24 \mathrm{~h}, \mathrm{CM}$ was replaced and $10 \mathrm{~mL}$ of $\mathrm{CM}$ or TNF- $\alpha$ solution was added to give, in the test wells, the final TNF- $\alpha$ concentration of $250 \mathrm{U} \cdot \mathrm{mL}^{-1}$. After an additional $24 \mathrm{~h}$, tumour cells were firmly adherent, had reached confluence and were approximately $2 \times 10^{5}$ cells $^{\cdot}$ well ${ }^{-1}$. LAK cells, generated as described above, were labelled with $100 \mathrm{mCi}$ of $\mathrm{Na}^{51}$ $\mathrm{CrO}_{4}$ (Amersham, Milan, Italy), washed twice with CM to remove unbound label, resuspended at the concentration of $2 \times 10^{5}$ cells $\cdot \mathrm{mL}^{-1}$ and added, in $1 \mathrm{~mL}$ aliquots, to tumour cell monolayers. Blocking experiments were performed by adding anti-CD54 MoAbs $\left(20 \mu \mathrm{g} \cdot \mathrm{mL}^{-1}\right)$ to tumour cell cultures, or anti-CD18 $\left(10 \mu \mathrm{g} \cdot \mathrm{mL}^{-1}\right)$, or anti-CD11a $\left(10 \mu \mathrm{g} \cdot \mathrm{mL}^{-1}\right)$ MoAbs to LAK cells $1 \mathrm{~h}$ before the beginning of LAK cells/tumour cells co-incubation. After $90 \mathrm{~min}$ of incubation $\left(37^{\circ} \mathrm{C}, 5 \% \mathrm{CO}_{2}\right)$, the wells were gently washed five times with warm HBSS to remove nonadherent LAK cells, and the adherent cells were lysed with $1 \%$ sodium dodecyl sulphate (SDS) solution. The entire contents of the wells were carefully harvested and radio-activity was counted in a gamma counter (Beckman 5500, Irvine, CA, USA). The percentage of adherent LAK cells was calculated using the formula: $\mathrm{A} / \mathrm{B} \times 100$, where $\mathrm{A}$ is the counts per minute (cpm) in lysate of test wells and B is the total cpm of $2 \times 10^{5}{ }^{51} \mathrm{Cr}$-labelled LAK cells. All tests were run in triplicate cultures and variability was always $<15 \%$.

\section{LAK-cytotoxicity assay}

The cytotoxic activity of LAK cells on NCI H460, NCI H211 and NCI H838 NSCLC cells was determined by a $4 \mathrm{~h}{ }^{51} \mathrm{Cr}$ release assay. After incubation with TNF$\alpha\left(250 \mathrm{U} \cdot \mathrm{mL}^{-1}\right)$, NCI H460, NCI H211 and NCI H838 (target cells) were washed twice with $\mathrm{CM}$, resuspended in a small volume and labelled with $100 \mathrm{mCi}$ of $\mathrm{Na}^{51} \mathrm{CrO}_{4}$ (Amersham, Milan, Italy). After $1 \mathrm{~h}\left(37^{\circ} \mathrm{C}, 5 \% \mathrm{CO}_{2}\right)$, target cells were washed twice with $\mathrm{CM}$, resuspended at the concentration of $5 \times 10^{4}$ cells $\cdot \mathrm{mL}^{-1}$ and $0.1 \mathrm{~mL}$ aliquots of target cell suspension were delivered in roundbottomed 96-well plates (Sterilin, Feltham, UK). LAK cells (effector cells), at effector:target (E:T) cell ratios of $25: 1$, were added to target cells to give a total final volume of $0.2 \mathrm{~mL} \cdot$ well $^{-1}$. Blocking experiments were performed by adding anti-CD54 $\left(20 \mu \mathrm{g} \cdot \mathrm{mL}^{-1}\right)$, anti-CD18 $\left(10 \mu \mathrm{g} \cdot \mathrm{mL}^{-1}\right)$, or anti-CD11a $\left(10 \mu \mathrm{g} \cdot \mathrm{mL}^{-1}\right) \mathrm{MoAbs}$, or sICAM-1 (50 ng.mL $\left.{ }^{-1}\right)$ to tumour cells $1 \mathrm{~h}$ before the beginning of LAK and tumour cell co-incubation. Soluble ICAM-1 was prepared by diluting the standard sICAM-1 of the ELISA kit (British Bio-technology). After $4 \mathrm{~h}$ of incubation $\left(37^{\circ} \mathrm{C}, 5 \% \mathrm{CO}_{2}\right)$, assay plates were gently centrifuged and $0.1 \mathrm{~mL}$ aliquots were harvested from each well and counted in a gamma counter. Cytotoxic index (CI) was determined as: $\mathrm{CI}=\mathrm{A}-\mathrm{B} / \mathrm{C}$ $\mathrm{B} \times 100$, where $\mathrm{A}$ is the ${ }^{51} \mathrm{Cr}$ release (expressed in $\mathrm{cpm}$ ) under the experimental condition, $\mathrm{B}$ is the spontaneous ${ }^{51} \mathrm{Cr}$ release, and $\mathrm{C}$ is the maximum releasable ${ }^{51} \mathrm{Cr}$, as determined by incubation of target cells with $1 \%$ SDS solution. Spontaneous ${ }^{51} \mathrm{Cr}$ release never exceeded $4 \%$ per hour. All tests were run in quadruplicate and variability between replicates did not exceed $15 \%$.

\section{Statistical analysis}

Comparisons were made by the Student's t-test; a p value $<0.05$ was considered as significant.

\section{Results}

\section{Cytofluorimetric analysis of baseline and cytokine-induced} ICAM-1 expression by lung cancer cell lines

We first examined the baseline expression of ICAM-1 in lung cancer cell lines (table 1). While all the investigated SCLC cell lines were negative for ICAM-1 expression, 4 of the 5 NSCLC cell lines expressed ICAM-1 under normal cell culture conditions. Interestingly, the only ICAM-1-negative NSCLC cell line was the NCI H460, a large cell carcinoma line expressing neuroendocrine markers [17].

ICAM-1 expression, as assessed by measuring mean fluorescence intensity, was increased by TNF- $\alpha$ (250 $\mathrm{U} \cdot \mathrm{mL}^{-1}, 16 \mathrm{~h}$ ) in 2 of the 5 NSCLC lines (NCI H460 and NCI H838) and, to a lesser extent, in another two lines (NCI H358 and NCI H157). A representative cytofluorimetric analysis of ICAM-1 expression by the NCI H460 and NCI H838 cell lines is shown in figure 1.

In contrast, TNF- $\alpha$ did not modify ICAM- 1 expression in 4 of the 5 SCLC cell lines (table 1). Interestingly, the only SCLC line in which TNF-mediated upregulation of ICAM-1 expression (by a factor of 4.6) was observed was the "variant" NCI H211 cell line [17]. As regards the effects of IFN- $\gamma\left(250 \mathrm{U} \cdot \mathrm{mL}^{-1}, 16 \mathrm{~h}\right)$, an upregulation of ICAM-1 expression was observed in only 1 of the 5 NSCLC lines (Sk-Mes1, by a factor of 1.8), as opposed to 4 out of 5 SCLC lines (by a factor ranging 2.8-8.3). ICAM-1 expression was unaffected by GM-CSF in all of the cell lines investigated.

\section{Baseline and cytokine-induced sICAM-1 production by lung cancer cell lines}

The concentration of sICAM-1 in cell-free culture media of lung cancer cell lines was measured under baseline culture conditions and after stimulation with inflammatory cytokines (table 2). Soluble ICAM-1 was $<2.5$ 
Table 1. - ICAM-1 expression by cultured lung cancer cell lines and modulation by inflammatory cytokines

\begin{tabular}{|c|c|c|c|c|c|c|c|c|}
\hline \multirow{2}{*}{\multicolumn{2}{|c|}{ Lung cancer cell line }} & \multicolumn{7}{|c|}{ ICAM-1 expression log mean fluorescence intensity } \\
\hline & & \multirow{2}{*}{ Baseline } & \multicolumn{2}{|c|}{$+\mathrm{TNF}-\alpha\left(250 \mathrm{U} \cdot \mathrm{mL}^{-1}\right)$} & \multicolumn{2}{|c|}{$+\operatorname{IFN}-\gamma\left(250 \mathrm{U} \cdot \mathrm{mL}^{-1}\right)$} & \multicolumn{2}{|c|}{$+\mathrm{GM}-\mathrm{CSF}\left(500 \mathrm{U} \cdot \mathrm{mL}^{-1}\right)$} \\
\hline NSCLC & & & & & & & & \\
\hline NCI H460 & Large cells with N.E. features & 8.4 & 38.9 & $(4.6)$ & 9.2 & $(1.1)$ & 7.0 & $(0.8)$ \\
\hline NCI H838 & Adenocarcinoma & 24.7 & 51.6 & $(2.1)$ & 31.5 & $(1.3)$ & 22.7 & $(0.9)$ \\
\hline NCI H358 & Bronchioloalveolar & 16.8 & 24.9 & $(1.5)$ & 20.3 & $(1.2)$ & 18.1 & (1.1) \\
\hline Sk Mes-1 & Squamous & 15.3 & 18.3 & $(1.2)$ & 27.8 & $(1.8)$ & 12.6 & $(0.8)$ \\
\hline $\begin{array}{l}\text { NCI H157 } \\
\text { SCLC }\end{array}$ & Squamous & 17.3 & 28.6 & $(1.7)$ & 16.6 & $(0.96)$ & 21.2 & $(1.2)$ \\
\hline NCI H69 & Classic & 7 & 7 & (1) & 19.4 & $(2.8)$ & 7 & (1) \\
\hline NCI H526 & Classic & 8 & 8 & (1) & 11.6 & (1.4) & 8 & (1) \\
\hline NCI H187 & Classic & 6 & 6 & (1) & 27.5 & (4.6) & 6 & (1) \\
\hline NCI H146 & Classic & 3 & 3 & (1) & 25.0 & $(8.3)$ & 4 & (1.3) \\
\hline NCI H211 & Variant & 4 & 18.5 & (4.6) & 14.7 & (3.7) & 5 & (1.2) \\
\hline
\end{tabular}

Tumour cells were exposed to cytokines $(16 \mathrm{~h})$ and surface expression of ICAM-1 was measured by flow cytometry. Data are expressed as log mean fluorescence intensity of representative experiments, and ratio to baseline expression in parenthesis. ICAM1: intercellular adhesion molecule-1; TNF- $\alpha$ : tumour necrosis factor- $\alpha$; IFN- $\gamma$ : interferon- $\gamma$; GM-CSF: granulocyte/macrophage colony-stimulating factor; NSCLC: non-small cell lung cancer; SCLC: small cell lung cancer; NCI: National Cancer Institute. N.E: neuroendocrine.

$\mathrm{ng} \cdot \mathrm{mL}^{-1}$ at baseline and after incubation with cytokines in 4 out of 4 "classic" SCLC cell lines and in NCI H211, the "variant" SCLC line characterized by TNF- $\alpha$-induced upregulation of surface ICAM-1 expression. Under baseline conditions, sICAM-1 was $<2.5 \mathrm{ng} \cdot \mathrm{mL}^{-1}$ in 3 out of 5 NSCLC cell lines, while low levels of sICAM-1 were detected in media of NCI H460 and NCI H838 NSCLC lines. As expected, GM-CSF (500 U.mL-1, $16 \mathrm{~h}$ ) did not modify sICAM-1 release by NSCLC lines. IFN- $\gamma(250$ $\mathrm{U} \cdot \mathrm{mL}^{-1}, 16 \mathrm{~h}$ ) induced sICAM-1 release by NCI H838 and Sk Mes-1 NSCLC cells, while it was unable to do so in the remainder. TNF- $\alpha\left(250 \mathrm{U} \cdot \mathrm{mL}^{-1}, 16 \mathrm{~h}\right)$ did not modify sICAM-1 release by 4 out of 5 NSCLC lines, but stimulated sICAM-1 release by the NCI H838 line by a factor of 2.7 (table 2).

a)

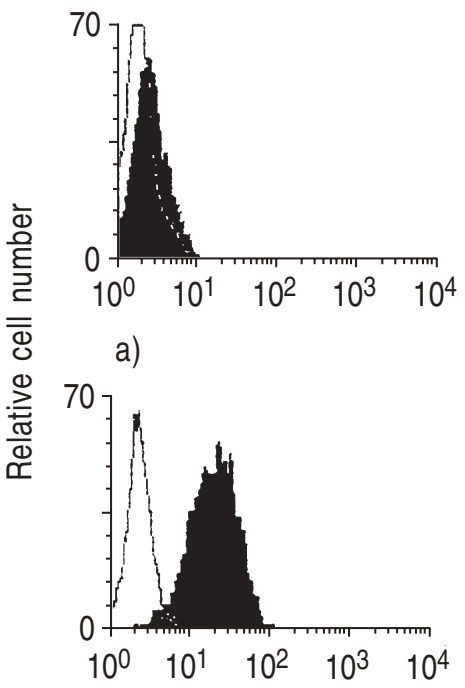

b)

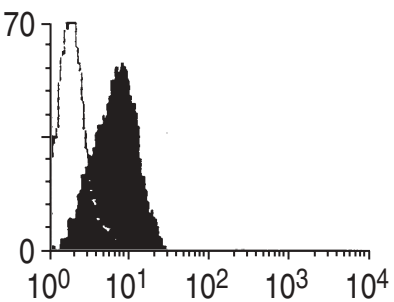

b)

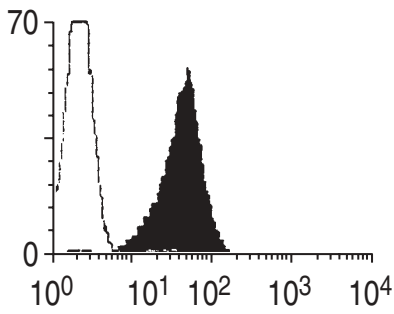

By combining the results presented in tables 1 and 2 it was clear that, while in NCI H838 the increased surface expression of ICAM-1 was paralleled by significant release of sICAM-1, no significant release of sICAM-1 occurred despite TNF- $\alpha$-induced upregulation of ICAM1 expression on the surface of NCI H460 and NCI H211 cells.

Effects of upregulation of ICAM-1 expression by NCI H460 and NCI H211 cell lines on adhesion to LAK cells and susceptibility to LAK cytotoxicity

To investigate the functional consequences of TNF$\alpha$-induced upregulation of ICAM-1 expression on the surface of lung cancer cells in the absence of sICAM-1
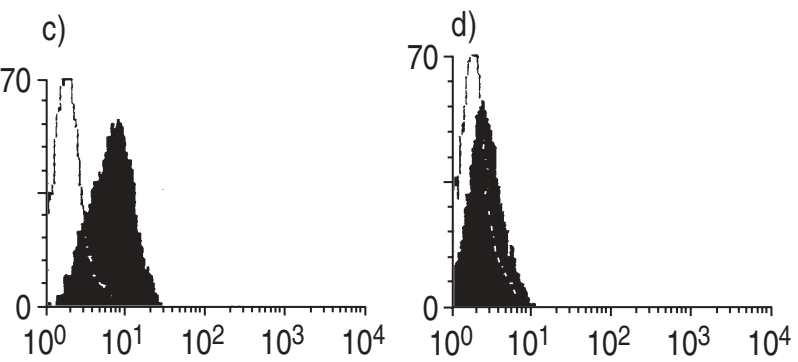

c)
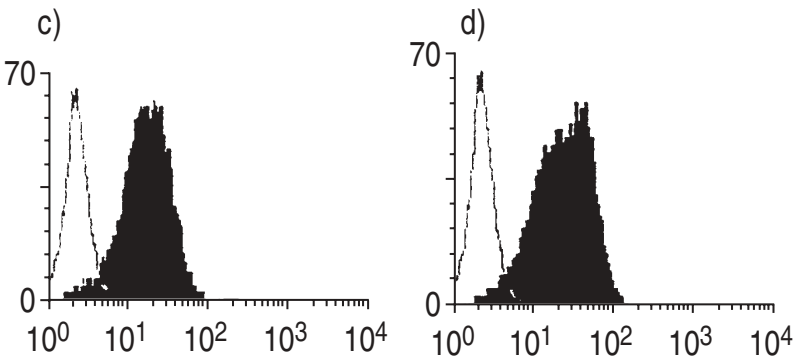

Log fluorescence intensity

Fig. 1. - A representative cytofluorimetric analysis of surface ICAM-1 expression by NCI H460 (upper panels) and NCI H838 (lower panels) NSCLC cell lines. Cells were incubated with: a) complete medium; b) TNF- $\alpha$; c) IFN- $\gamma$; or d) GM-CSF, and labelled with phycoerythrin (PE)conjugated mouse anti-human ICAM-1 MoAb. Stained cells (shaded portion) were analysed on a FACStar gated to exclude nonviable cells and were compared to controls prepared by incubating the cells with an irrelevant isotype-matched MoAb (open portion). Results are presented as relative cell number (y-axis) versus log fluorescence intensity (x-axis). ICAM-1: intercellular adhesion molecule-1; NCI: National Cancer Institute; NSCLC: non-small cell lung cancer; TNF- $\alpha$ : tumour necrosis factor- $\alpha$; IFN- $\gamma$ : interferon- $\gamma$; GM-CSF: granulocyte/macrophage colony-stimulating molecule-1; MoAb: monoclonal antibody; FACS: fluorescence-activated cell sorter. 
Table 2. - Soluble ICAM-1 production by cultured lung cancer cell lines and modulation by inflammatory cytokines

\begin{tabular}{|c|c|c|c|c|c|}
\hline \multirow{2}{*}{\multicolumn{2}{|c|}{ Lung cancer cell line }} & \multicolumn{4}{|c|}{ sICAM-1 production $\mathrm{ng} \cdot \mathrm{mL}^{-1}$} \\
\hline & & Baseline & $+\mathrm{TNF}-\alpha\left(250 \mathrm{U} \cdot \mathrm{mL}^{-1}\right)$ & $+\mathrm{IFN}-\gamma\left(250 \mathrm{U} \cdot \mathrm{mL}^{-1}\right)$ & $+\mathrm{GM}-\mathrm{CSF}\left(500 \mathrm{U} \cdot \mathrm{mL}^{-1}\right)$ \\
\hline \multicolumn{6}{|l|}{ NSCLC } \\
\hline NCI H460 & Large cells with N.E. features & $2.9 \pm 0.2$ & $3.0 \pm 0.4(1)$ & $3.1 \pm 0.1(1.1)$ & $3.3 \pm 0.3(1.1)$ \\
\hline NCI H838 & Adenocarcinoma & $4.8 \pm 1$ & $13.1 \pm 1.2(2.7)^{*}$ & $10.8 \pm 0.4(2.2)^{*}$ & $4.3 \pm 0.8(0.9)$ \\
\hline NCI H358 & Bronchioloalveolar & $<2.5$ & $3.5 \pm 0.7$ & $3.2 \pm 0.7$ & $<2.5$ \\
\hline Sk Mes-1 & Squamous & $<2.5$ & $2.9 \pm 0.4$ & $6.0 \pm 1.1$ & $2.7 \pm 0.1$ \\
\hline NCI H157 & Squamous & $<2.5$ & $<2.5$ & $<2.5$ & $<2.5$ \\
\hline \multicolumn{6}{|c|}{ SCLC } \\
\hline NCI H69 & Classic & $<2.5$ & $<2.5$ & $<2.5$ & $<2.5$ \\
\hline NCI H526 & Classic & $<2.5$ & $<2.5$ & $<2.5$ & $<2.5$ \\
\hline NCI H187 & Classic & $<2.5$ & $<2.5$ & $<2.5$ & $<2.5$ \\
\hline NCI H146 & Classic & $<2.5$ & $<2.5$ & $<2.5$ & $<2.5$ \\
\hline NCI H211 & Variant & $<2.5$ & $<2.5$ & $<2.5$ & $<2.5$ \\
\hline
\end{tabular}

Tumour cells were exposed to cytokines and, after $16 \mathrm{~h}$, cell-free culture supernatants were harvested. Soluble ICAM-1 concentrations were measured by ELISA. Data are expressed as mean \pm SEM, and ratio to baseline expression in parenthesis. sICAM-1: soluble intercellular adhesion molecule-1; ELISA: enzyme-linked immunosorbent assay. For further definitions see legend to table 1. *: $\mathrm{p}<0.05$ by the Student's t-test.
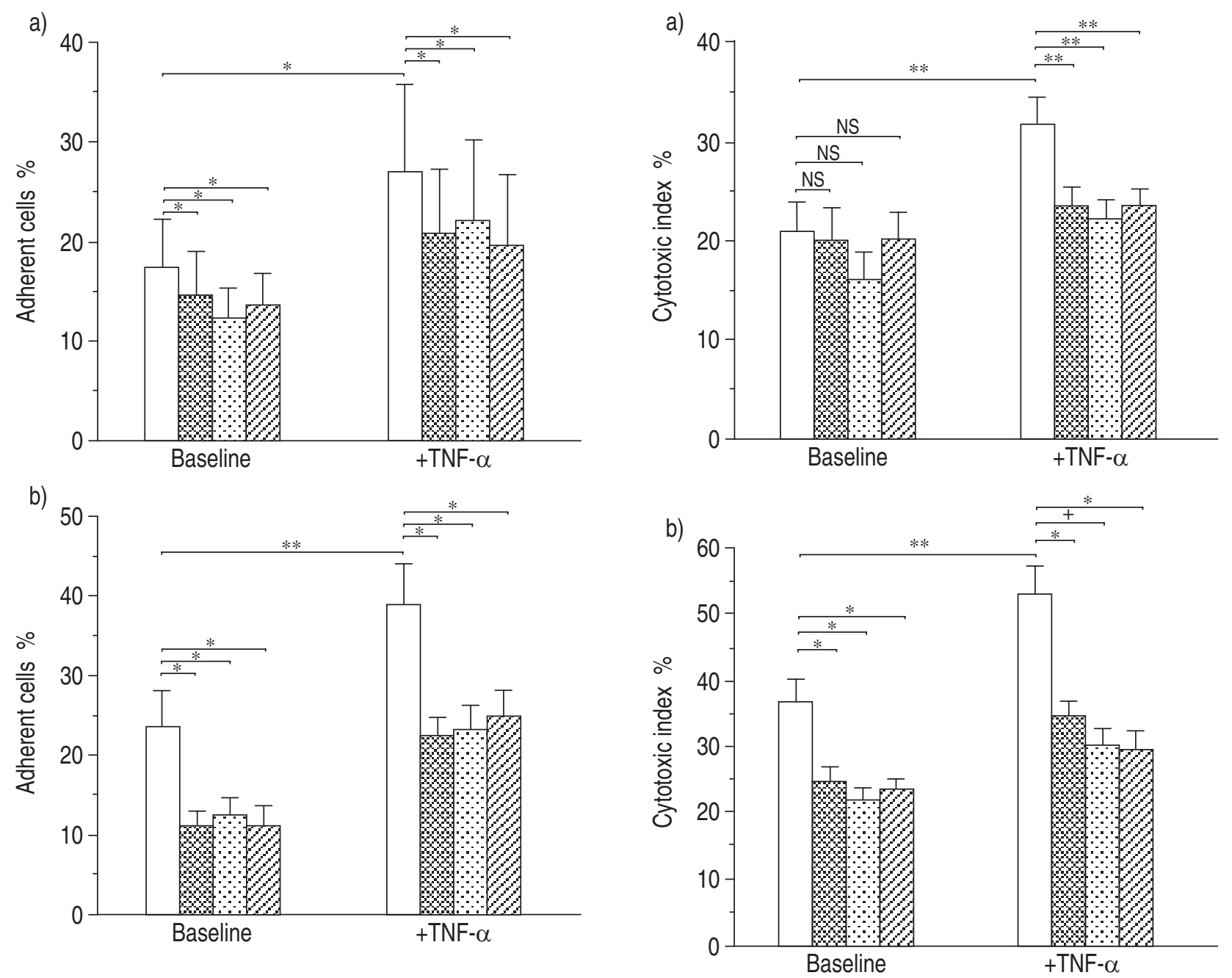

Fig. 2. - Adhesion of: a) NCI H460 cells; and b) NCI H211 cells to allogeneic LAK cells. After incubation with control medium (Baseline) or with TNF- $\alpha\left(250 \mathrm{U} \cdot \mathrm{mL}^{-1}\right)$, adherent tumour cells were co-incubated with $\mathrm{Na}^{51} \mathrm{CrO}_{4}$-labelled allogeneic LAK cells in the absence $(\square)$ or presence of excess anti-CD54 (\$) , anti-CD18 ( $\because$ ), or antiCD11a ( $)$ MoAbs. After 90 min, conjugate formation was measured as described in Materials and methods. Results are expressed as mean \pm SEM of four separate experiments. Comparisons were made by the Student's t-test for paired data; *: $\mathrm{p}<0.05 ; * *$ : $<<0.01$. LAK: lymphokine-activated killer. For further definitions see legend to figure 1.

Fig. 3. - Cytotoxic activity of allogeneic LAK cells on: a) NCI H460 cells; and NCI H211 cells. After incubation with control medium (Baseline) or TNF- $\alpha$ (250 U.mL $\left.\mathrm{mL}^{-1}\right), \mathrm{Na}^{51} \mathrm{CrO}_{4}$-labelled tumour cells were co-incubated with allogeneic LAK cells in the absence $(\square)$ or presence of excess anti-CD54 ( $\mathrm{XS}$ ), anti-CD18 ( $\because \because)$, or anti-CD11a (Z2) MoAbs. After $4 \mathrm{~h}$, cytotoxicity was measured as described in Materials and methods. Results are expressed as mean \pm SEM of four separate experiments. Comparisons were made by the Student's t-test for paired data; Ns: not significant; $*$ : $\mathrm{p}<0.05 ;{ }^{+}: \mathrm{p}<0.02 ;{ }^{*}: \mathrm{p}<0.01$. For definitions see legends to figures 1 and 2 . 
production, the percentage of LAK cells which adhere to monolayers of NCI H460 and NCI H211 was evaluated at baseline and after incubation with TNF- $\alpha$ (250 $\mathrm{U} \cdot \mathrm{mL}^{-1}, 16 \mathrm{~h}$ ) in the absence or in the presence of antiCD54, anti-CD18 or anti-CD11a MoAbs. The adherence of LAK cells to NCI H460 and NCI H211 cells was significantly increased by TNF- $\alpha$; in addition, the adhesion of LAK cells was significantly reduced by anti-CD54, anti-CD18, or anti-CD11a MoAbs, both at baseline and after TNF stimulation (fig. 2a). The susceptibility of NCI H460 and NCI H211 to LAK cell cytotoxicity was significantly increased by TNF (fig. 2b).

In addition, while at baseline the susceptibility of NCI

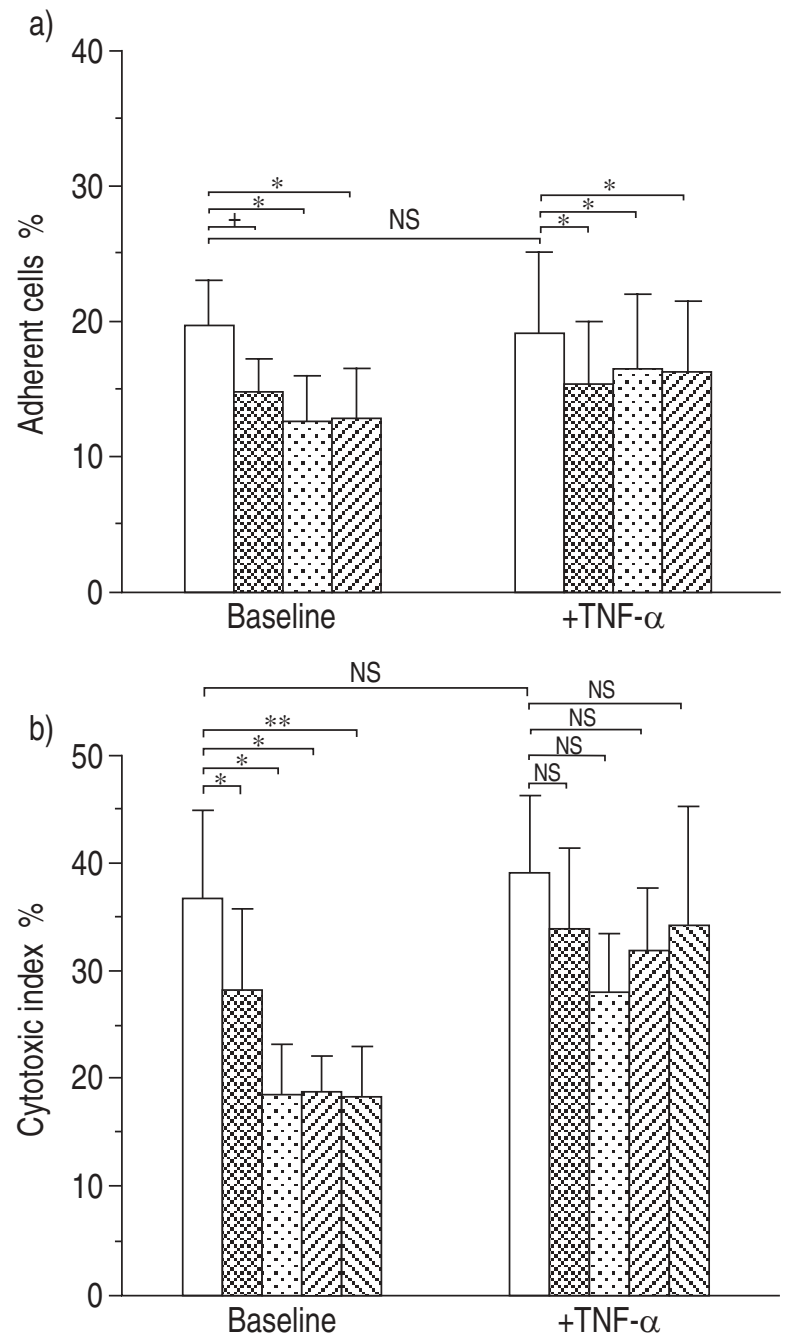

Fig. 4. - a) Adhesion of NCI H838 NSCLC cells to allogeneic LAK cells. After incubation with control medium (Baseline) or with TNF$\alpha\left(250 \mathrm{U} \cdot \mathrm{mL}^{-1}\right)$, adherent tumour cells were co-incubated with $\mathrm{Na}^{51} \mathrm{CrO}_{4}$ labelled allogeneic LAK cells in the absence $(\square)$ or presence of ex-

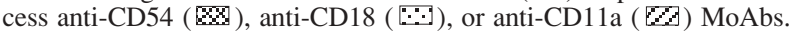
After $90 \mathrm{~min}$, conjugate formation was measured as described in Materials and methods. b) Cytotoxic activity of allogeneic LAK cells on NCI H838 cells. After incubation with control medium (Baseline) or TNF- $\alpha\left(250 \mathrm{U} \cdot \mathrm{mL}^{-1}\right), \mathrm{Na}^{51} \mathrm{CrO}_{4}$-labelled tumour cells were co-incubated with allogeneic LAK cells in the absence or presence of excess anti-CD54 ( $\$$ ), anti-CD18 ( $\because \because)$ ), or anti-CD11a ( $\angle \subset$ ) exogenous sICAM-1 ( 3 ) MoAbs. After $4 \mathrm{~h}$, cytotoxicity was measured as described in Materials and methods. Results are expressed as mean \pm SEM of four separate experiments. Comparisons were made by the Student's t-test for paired data; Ns: not significant; *: $\mathrm{p}<0.05 ;+$ : $\mathrm{p}<0.02$; **: $\mathrm{p}<0.01)$. sICAM-1: soluble intercellular adhesion molecule-1. For further definitions see legends to figures 1 and 2 .
H460 to LAK cell cytotoxicity was not modified by antiCD54, anti-CD18, or anti-CD11a MoAbs, the same antibodies significantly reduced LAK-mediated cytotoxicity on TNF- $\alpha$-treated NCI H460 cells and on NCI H211, both at baseline and after TNF- $\alpha$ stimulation (fig. 3).

Effects of upregulation of ICAM-1 expression by NCI H838 on adhesion to LAK cells and susceptibility to LAK cytotoxicity

To investigate the functional consequences of TNF- $\alpha$ induced upregulation of ICAM-1 expression on the surface of lung cancer cells in the presence of sICAM-1 production, the percentage of LAK cells which adhere to monolayers of NCI H838 was evaluated at baseline and after incubation with TNF- $\alpha\left(250 \mathrm{U} \cdot \mathrm{mL}^{-1}, 16 \mathrm{~h}\right)$ in the absence or in the presence of anti-CD54, anti-CD18 or anti-CD11a MoAbs (fig. 4a). In contrast to the results obtained with NCI H460 and NCI H211, no increase in binding to allogeneic LAK cells was observed when baseline and TNF- $\alpha$-treated NCI H838 cells were compared. Anti-CD54, anti-CD18 and anti-CD11a MoAbs were able to reduce adhesion both at baseline and after TNF- $\alpha$-stimulation.

The susceptibility of NCI H838 and TNF- $\alpha$-treated (250 U.mL-1, 16 h) NCI H838 to LAK cell cytotoxicity was then evaluated in the absence or in the presence of anti-CD54, anti-CD18 or anti-CD11a MoAbs, or exogenous sICAM-1 (fig. 4b). This experimental condition was added because sICAM- 1 produced by TNF- $\alpha$-treated NCI H838 cells was probably removed during preparation of target cells for cytotoxicity assays. No increase in the susceptibility to LAK cell cytotoxicity was observed when baseline and TNF- $\alpha$-treated NCI H838 cells were compared. Moreover, anti-CD54, anti-CD18 and antiCD11a MoAbs, and exogenous sICAM-1 were able to reduce LAK cell cytotoxicity at baseline, but not after TNF- $\alpha$ stimulation.

\section{Discussion}

In the present study, the surface expression of ICAM1 and the production of SICAM-1 by five SCLC and five NSCLC cell lines and their modulation by the inflammatory cytokines TNF- $\alpha$, IFN- $\gamma$, and GM-CSF was investigated. In agreement with a previous study [9], it was found that, under baseline culture conditions, SCLC lines do not express ICAM-1. In contrast, it was found that 4 of the 5 NSCLC cell lines investigated spontaneously express ICAM-1 and the only negative NSCLC line was NCI H460, a large cell carcinoma line expressing neuroendocrine markers [17]. This finding is at variance with the results of SCHARDT et al. [9], who described high levels of spontaneous ICAM-1 expression in other large cell carcinoma lines. This discrepancy may be explained by the heterogeneous differentiation of large cell carcinomas [22]; indeed, the expression of neuroendocrine markers by NCI H460 makes this particular cell line phenotypically closer to SCLC.

Preliminary dose-response and time-course experiments on NCI H460 showed that maximal induction of ICAM-1 expression occurs after incubation with 250 $\mathrm{U} \cdot \mathrm{mL}^{-1} \mathrm{TNF}-\alpha$ for $16 \mathrm{~h}$ (data not shown); these conditions of exposure to TNF- $\alpha$ were chosen for subsequent 
experiments on adhesion to LAK cells and susceptibility to LAK cell cytotoxicity.

A difference in behaviour between SCLC and NSCLC lines was also observed with respect to modulation of ICAM-1 expression by inflammatory cytokines. Whilst in SCLC lines IFN- $\gamma$, but not TNF- $\alpha$, was a powerful inducer of ICAM-1 expression, a trend to an opposite behaviour was observed in NSCLC lines. An exception to this general rule was represented by NCI H211, a "variant" SCLC line [17], whose expression of ICAM-1 was upregulated by TNF- $\alpha$. It is unclear why TNF- $\alpha$ is unable to increase ICAM-1 expression in all "classic" SCLC lines tested. One might postulate that "classic" SCLC lines lack specific receptors for TNF- $\alpha$; indeed, TNF- $\alpha$ is not cytotoxic for SCLC lines and TNF- $\alpha$ receptors are present in only $25 \%$ of "classic" SCLC lines [23]. However, we did not observe TNF- $\alpha$-mediated induction of ICAM-1 in the NCI H187, the only "classic" SCLC line expressing high-affinity TNF- $\alpha$ receptors [23], suggesting that, besides the presence of TNF- $\alpha$ receptors, other factors may play a role in TNF- $\alpha$-mediated regulation of ICAM-1 expression in tumour cells.

Although the expression of ICAM-1 by lung cancer cells and the parallel production of inflammatory cytokines by tumour-infiltrating mononuclear cells have been investigated previously in surgical samples of NSCLC, the in vivo role of regulation of ICAM-1 expression on lung cancer cells is unknown. VITOLO et al. [24] reported that ICAM-1 is expressed by squamous cell carcinomas and that LFA-1-positive tumour infiltrating lymphocytes actively express messenger ribonucleic acid (mRNA) transcripts for IFN- $\gamma$, suggesting that the ability of squamous carcinoma cells to express ICAM-1 is associated with the recruitment and activation of tumour infiltrating lymphocytes, which, in turn, might upregulate ICAM1 expression by tumour cells. In addition, PAssLICK et al. [25] reported that the expression of ICAM-1 in lung adenocarcinoma cells is selectively increased in tumour areas heavily infiltrated with leucocytes, suggesting that the expression of ICAM-1 on primary lung tumour cells might be induced or amplified by inflammatory cytokines released by tumour infiltrating lymphocytes. However, since ICAM-1 expression on tumour cells was not correlated to the rate of tumour recurrence after surgery and overall survival, evidence is missing that the cellcell interactions facilitated by ICAM- 1 can positively influence the clinical course of the disease.

Consistent with the results of cytofluorimetric analysis, SCLC lines did not release significant amounts of sICAM-1 at baseline and after incubation with cytokines. Among the cell lines investigated, NCI H460 and NCI H211 showed the greatest inducibility of membrane ICAM-1 expression after incubation with TNF$\alpha$, but did not release significant amounts of sICAM-1 under the same stimulus. In marked contrast, in NCI $\mathrm{H} 838$, TNF- $\alpha$-mediated upregulation of cell surface expression of ICAM-1 was paralleled by the release of significant amounts of sICAM-1 in culture media. To our knowledge, this is the first analysis of SICAM- 1 release by lung cancer cell lines of heterogeneous types and the first description of the ability of a NSCLC line, namely NCI H838, to release sICAM-1 after incubation with cytokines. Although the different experimental conditions do not allow definite conclusions to be drawn, the release of sICAM-1 by NCI H838 NSCLC line is comparable to the release by melanoma cell lines [26]. It is unclear why TNF- $\alpha$-treated NCI H460 and NCI H211 cells did not release high amounts of sICAM-1 despite significant TNF- $\alpha$-induced upregulation of surface ICAM-1 expression. Interestingly, in previous studies, no significant correlation was found between SICAM-1 release and cellular ICAM-1 expression in TNF- $\alpha$-treated melanoma cell lines [26].

The characteristics of NCI H-460, NCI H211, and NCI $\mathrm{H}-838$ cells made it possible to investigate the effects of upregulation of surface ICAM-1 expression and sICAM1 release on the adhesion of lung cancer cells to allogeneic LAK cells and on susceptibility to LAK-cell cytotoxicity. It was found that increased surface expression of ICAM-1 on NCI H460 and H211 cells is followed by increased adherence to LAK cells and increased susceptibility to LAK-cell cytotoxicity, and these effects are related, at least partly, to ICAM-1/LFA-1 interaction, as suggested by the results of blocking experiments with the anti-CD54, anti-CD18 and anti CD11a MoAbs. In contrast, when baseline and TNF- $\alpha$-treated NCI H838 cells were compared, no increase in adherence to LAK cells and no increase in susceptibility to LAK cell cytotoxicity was observed despite a significant increase in ICAM-1 surface expression. One possible explanation for these results is that sICAM-1 released by the NCI H838 cells may interact with LFA-1 present on LAK cells, thus affecting the adhesion process. In agreement with this hypothesis, in the present experiments, exogenous sICAM-1 reduced susceptibility of untreated NCI H838 cells to LAK cytotoxicity. These results confirm and extend previous data by BECKER et al. [14] who demonstrated that purified sICAM-1 reduces adhesion of melanoma cells to LAK cells and susceptibility to LAK cytotoxicity [14]. These findings suggest that sICAM-1 release may be one mechanism by which tumour cells escape physical interaction with cytotoxic cells and its functional consequences. Interestingly, increased serum levels of sICAM-1 have been recognized as an unfavourable prognostic marker in patients with melanoma [16], and with renal cell carcinoma [27]. Further studies are needed to evaluate the possible clinical role of the assessment of serum levels of sICAM-1 in patients with lung cancer.

Although the results of the present study suggest a relationship between adhesion of tumour cells to LAK cells and susceptibility to LAK cell cytotoxicity, the relationship between the latter phenomenon and ICAM-1 expression by tumour cells is incompletely understood. Firstly, ICAM-1 expression does not correlate with the susceptibility of different tumour cell targets to LAK cell cytotoxicity [28]; interestingly, in our studies, whilst at baseline NCI H460 cells do not express surface ICAM-1, they adhere to LAK cells and are lysed by LAK cells. Secondly, cytokine-mediated upregulation of ICAM-1 surface expression on bladder cancer cells is followed by increased binding to LAK cells, but not by increased susceptibility to LAK cell cytotoxicity [29]. Thirdly, Metha et al. [30] have reported that prevention of post-translational addition of N-linked oligosaccharides to ICAM-1 by treatment with tunicamycin is followed by a dramatic increase in susceptibility of tumour targets to LAK cell cytotoxicity, in the absence of detectable modifications of ICAM-1 mediated binding capability. These findings suggest that carbohydrate modifications 
of ICAM-1 (or an alternative glycoprotein) may play an important role in the postbinding metabolic processes eventually resulting in the lysis of tumour targets. Moreover, besides ICAM-1, other counterreceptors of the LFA-1 molecule (such as ICAM-2 and ICAM-3) and additional heterogeneous mechanisms of intercellular adhesion probably play a role in the interaction between LAK and tumour cells. The characterization of the adhesion molecules involved in this interaction will be of great value in improving our understanding of the regulation of the susceptibility of tumour cells to lymphokineactivated killer cell cytotoxicity.

Acknowledgements: The authors are grateful to P.B. Carbone for providing the cell lines and to D. D'Amico for helpful discussions concerning this work.

\section{References}

1. Springer TA. Adhesion receptors of the immune system. Nature 1990; 346: 425-434.

2. Rothlein R, Dustin ML, Merlin SD, Springer TA. A human intercelluar adhesion molecule (ICAM-1) distinct from LFA. J Immunol 1986; 137: 1270-1274.

3. Singer KH. Interactions between epithelial cells and Tlymphocytes: role of adhesion molecules. J Leuk Biol 1990; 48: 367-374.

4. Billaud M, Calender A, Seigneurin JM, Lenoir GM. LFA1, LFA-3 and ICAM-1 expression in Burkitt's lymphoma. Lancet 1987; 11: 1327-1328.

5. Johnson JP, Stade BG, Holzmann B, Schwalbe W, Riethmuller G. De novo expression of intercellular adhesion molecule-1 in melanoma correlates with greater risk of metastasis. Proc Natl Acad Sci USA 1989; 86: 641-644.

6. Tomita Y, Nishiyama T, Watanabe H, Fujiwara M, Sato S. Expression of intercellular adhesion molecule-1 (ICAM1) on renal cell cancer: possible significance in host immune response. Int J Cancer 1990; 46: 1001-1006.

7. Schwaelbe W, Kerlin M, Meyer KH, Dippold W. De novo expression of intercellular adhesion molecule-1 (ICAM-1, CD54) in pancreas cancer. Int J Cancer 1993; 53: 328-333.

8. Jackson AM, Alexandrov AB, Gribben SC, Esuvarnathan $\mathrm{K}$, James K. Expression and shedding of ICAM-1 in bladder cancer and its immunotherapy. Int $J$ Cancer 1993; 55: 921-925.

9. Schardt C, Heymanns J, Schardt C, Rotsch M, Havemann $\mathrm{K}$. Differential expression of the intercellular adhesion molecule-1 (ICAM-1) in lung cancer cell lines of various histological types. Eur J Cancer 1993; 29A: 2250-2255.

10. Rothlein RM, Chajkowski M, O'Neill MM, Marlin SD, Mainolfi E, Merluzzi VJ. Induction of intercellular adhesion molecule- 1 on primary and continuous cell lines by inflammatory cytokines. J Immunol 1988; 141: 1665-1670.

11. Webb DSA, Mostowski HS, Gerrard TL. Cytokineinduced enhancement of ICAM-1 expression results in increased vulnerability of tumor cells to monocyte-mediated lysis. J Immunol 1991; 146: 3682-3686.

12. Jonjic N, Alberti S, Bernasconi S, et al. Heterogeneous susceptibility of human melanoma clones to monocyte cytotoxicity: role of ICAM-1 defined by antibody blocking and gene transfer. Eur J Immunol 1992; 22: 2255-2260.

13. Altomonte M, Gloghini A, Bertola G, et al. Differential expression of cell adhesion molecules CD54/CD11a and CD58/CD2 by human melanoma cells and functional role in their interaction with cytotoxic lymphocytes. Cancer Res 1993; 53: 3343-3348.

14. Becker JC, Dummer R, Hartmann M, Burg G, Schmidt
RE. Shedding of ICAM-1 from human melanoma cell lines induced by IFN- $\gamma$ and tumor necrosis factor- $\alpha$ : functional consequences on cell-mediated cytotoxicity. J Immunol 1991; 147: 4398-4401.

15. Giavazzi R, Chirivi RGS, Garofalo A, et al. Soluble intercelluar adhesion molecule-1 is released by human melanoma cells and is associated with tumor growth in nude mice. Cancer Res 1992; 52: 2682-2630.

16. Harning R, Mainolfi E, Bystryn JC, Henn M, Merluzzi VJ, Rothlein R. Serum levels of circulating intercellular adhesion molecule-1 in human malignant melanoma. Cancer Res 1991; 51: 5003-5005.

17. Carbone DP, Koros AMC, Linnoila I, Jewett P, Gazdar AF. Neural cell adhesion molecule expression and messenger RNA splicing patterns in lung cancer cell lines are correlated with neuroendocrine phenotype and growth morphology. Cancer Res 1991; 51: 6142-6149.

18. Carney DN, Leij LD. Lung cancer biology. Semin Oncol 1988; 15: 199-214.

19. Melis M, Gjomarkaj M, Pace E, Malizia G, Spatafora M. Increased expression of leukocyte function associated antigen-1 (LFA-1) and intercellular adhesion molecule-1 (ICAM-1) by alveolar macrophages in patients with pulmonary sarcoidosis. Chest 1991; 100: 910-916.

20. Damle NK, Doyle LV, Bradley EC. Interleukin-2 activated human killer cells are derived from phenotypically heterogeneous precursors. J Immunol 1986; 137: 2814-2822.

21. Kratikamont P, Shazo RDd, Banks DE, Chapman Y. Cytotoxic cell function in bronchogenic carcinoma. Chest 1987; 92: 90-94.

22. Gazdar AF, Linnoila RI. The pathology of lung cancer: changing concepts and newer diagnostic techniques. Semin Oncol 1988; 15: 215-225.

23. Giaccone G, Kadoyama C, Maneckjee RH, Venzon D, Alexander RB, Gazdar AF. Effects of tumor necrosis factor, alone or in combination with topoisomerase II targeted drugs, on human lung cancer cell lines. Int $J$ Cancer 1990; 46: 326-329.

24. Vitolo D, Palmieri MB, Ruco LR, Rendina E, Bonsignore $\mathrm{G}$, Baroni CD. Cytokine production and expression of adhesion molecules and integrins in tumor infiltrating lymphomononuclear cells of non-small cell carcinomas of the lung. Am J Pathol 1994; 145: 1-8.

25. Passlick B, Izbicki JR, Simmel S, et al. Expression of major histocompatibility class I and class II antigens and intecellular adhesion molecule-1 on operable non-small cell lung carcinomas: frequency and prognostic significance. Eur J Cancer 1994; 30A: 376-381.

26. Scheibenbogen C, Keilholz U, Meuer S, Dengler T, Tilgen W, Hunstein W. Differential expression and release of LFA-3 and ICAM-1 in human melanoma cell lines. Int J Cancer 1993; 54: 494-498.

27. Heicappel R, Podlinski J, Buszello H, Ackermann R. Cell surface expression and serum levels of intercellular adhesion molecule-1 in renal cell carcinoma. Urol Res 1994; 22: 9-15.

28. Quillet-Mary A, Cavarec L, Kermarrec N, et al. Target lysis by human LAK cells is critically dependent upon target binding properties, but LFA-1, LFA-3 and ICAM1 are not the major adhesion ligands on targets. Int $J$ Cancer 1991; 47: 473-479.

29. Campbell SC, Tanake K, Alexander JP, Edinger M, Tubbs $\mathrm{RR}$, Klein EA. Intercellular adhesion molecule-1 expression by bladder cancer cells: functional effects. J Urol 1994; 151: 1385-1390.

30. Metha BA, Collard HR, Negrin RS. The role of N-linked carbohydrate residues in lymphokine-activated killer cellmediated cytolysis. Cell Immunol 1994; 155: 95-110. 